\title{
STS and its Challenging Obligations: Pablo Schyfter Talks with Donald MacKenzie
}

\author{
PABLO SCHYFTER \\ UNIVERSITY OF EDINBURGH \\ DONALD MACKENZIE ${ }^{2}$ \\ UNIVERSITY OF EDINBURGH
}

\begin{abstract}
In a wide-ranging interview, Donald MacKenzie and Pablo Schyfter discuss the former's entry into science and technology studies (STS), the trajectory of the field since then, and his perspectives on its character today. MacKenzie recalls his discovery of STS through political activism, and his subsequent experiences at the young Edinburgh Science Studies Unit. He reflects on the field's development and defining moments of transition, divergence and accomplishment. In reflecting on the field's abilities, MacKenzie also considers STS's potential for activism and intervention, and the challenges that accompany attempts to influence those things that it studies. Most importantly, he discusses the moral obligations and responsibilities that accompany engagement with controversial topics, like his own work studying nuclear weaponry and financial markets. In his reflection piece, Schyfter focuses on the notion of obligations, and expands MacKenzie's views to discuss methodological, epistemic and critical duties. Schyfter suggests that ultimately STS is obliged to pursue complication and enable useful discomfort.
\end{abstract}

\section{Keywords}

interview; Donald MacKenzie; obligations; reflexivity; activism

\section{Early Days, Radical Ideas, and British Gas}

PS Why don't you tell me about how you became involved in STS?

DM I came to the University of Edinburgh in 1968 as an undergraduate, initially to study physics, though in the middle of that I shifted over to doing applied maths, which is what I graduated in. That was the time of the student movement. Obviously when you do a lot of oral history as your own research tool, which I do, when somebody else does

Pablo Schyfter, Email: p.schyfter@ed.ac.uk

2Donald MacKenzie, Email: DonaldMacKenziePA@ed.ac.uk

Copyright () 2018 (Pablo Schyfter, Donald MacKenzie). Licensed under the Creative Commons Attribution Noncommercial No Derivatives (by-nc-nd). Available at estsjournal.org. 
an oral history interview you sometimes start to worry about the reliability of all the historical evidence because you start to think, "do I really remember that?" So I'm hoping that what I'm about to tell you is factually correct. If I remember the sequence of events correctly, I went along to a series of meetings of the British Society for Social Responsibility in Science. I think it was an Edinburgh branch and David Edge was the key figure in it, and that brought me in touch with the Science Studies Unit.

PS What was your motivation to go to those meetings?

DM Because I was a radical, and it was a radical kind of group. I was a scientist, so therefore a radical perspective on science seemed attractive. Then in my third year as an undergraduate, purely as a complete outside course-I didn't get any credit for this part of my degree-I did Barry Barnes' Science Studies 2bh course in the sociology of science, and really terrifically enjoyed it. I was paid through the university by British Petroleum as a university apprentice, but I wasn't compelled to work for them at the end, so I decided not to and decided to pursue a PhD in the Science Studies Unit.

PS What was it like being a student at the SSU at that time?

DM It was tremendous. A lot of people find doing a $\mathrm{PhD}$ a really rather isolating kind of experience, and one of the great strengths of the Unit in that period was it wasn't at all like that. Those were the early years of the Strong Program in the sociology of scientific knowledge. As a PhD student working in that area you felt that what you were doing was contributing to something bigger than your own $\mathrm{PhD}$ project and that the faculty members-and very specifically Barry Barnes and David Bloor-were interested in what you were doing, not just in the way that any supervisor has to be interested in their students' work but because it was potentially helpful to them. There was a real feeling of collectivity.

PS So you felt like you were contributing to the Strong Program?

DM Yes.

PS What was the place of the SSU in relation to say other institutions or events at the time?

DM The one thing that particularly stands out I think is that this was also the time where the Science Policy Research Unit at the University of Sussex was rising to prominence, and the ethos of the Unit distinguished itself from, what at least for Edinburgh, was seen as the applied policy-oriented orientation of SPRU. This wasn't of course a universal view because David Edge always had that kind of angle to him, and there was a separate stream of work in the Unit led by David along with Harry Dickinson, who was in the science and engineering part of Edinburgh University. I think he was an engineer. Their focus was "appropriate technologies," as it was then called, for what would then have been called third-world countries. But that aside, the Unit had a sort of classically academic ethos to it.

PS What prompted your choice of research focus?

DM Very simply, having just done a science-maths degree, I just thought it would make sense to make my focus something I'd learned about during my undergraduate studies. At that point there was a certain vogue for studies of scientific specialization and the emergence 
of new scientific specialties. And I knew enough historically to know that statistics was one of those new scientific specialties; it wasn't more than a century old. So that was the original plan for the PhD: to do the study of the emergence of statistics construed as the emergence of a new scientific specialism. In my initial exploration in the area I quickly learned that the leaders of three successive generations of British statisticians-Francis Galton, Karl Pearson and R.A. Fisher-had all been eugenicists. And then at something like the end of my first term as a PhD student, Ruth Schwartz Cowan's paper in Isis on the influence of eugenics on Francis Galton's statistics came out. Ruth's paper enabled me to refashion the study of scientific specializations, although I still did that to some extent, more into a sociology of knowledge study, because I realized the really interesting question was, "what influence did the commitment of British statisticians to eugenics have over their development of mathematical statistics?"

PS One of the things that we have been finding, that people have been telling us, is the importance of meetings at this time, for bringing people together in different countries, particularly transatlantic relationships. Did you participate in any meetings at this time?

DM Not much, no. If I remember rightly I had no conference funding as a PhD. I had a scholarship from the Carnegie Trust for the University of Scotland but if I remember rightly I could be paid for research travel but not I think to attend conferences. David Edge very kindly introduced me to various predominantly history of science departments, in part the nascent STS departments in the US, so I did go on one rather good fun trip giving effectively departmental seminars in four US departments. But it was actually quite some time before I attended my first joint meeting. There were some early meetings about sociological perspectives on maths in particular that were quite important and had impact. For example, the meeting of the Technical University of Berlin, organized by Herbert Mehrtens was good like that. There are certainly some meetings that do stand out. There are some meetings you think, "what the hell was that about?" but the meeting at Bath University say, that was where quite a bit of the early ethnographic micro-sociology of science stuff was presented. Not the very early Bruno Latour stuff but stuff done by people who lived in Britain. Another very important meeting for me was the meeting at the Technical University Twente in 1987. That's the one that led to the book The Social Shaping of Technological Systems. It was quite some time before I went to a meeting of the Society for Social Studies of Science, so that was less of an influence on me than perhaps it was on other people. A basic financial reason was the availability of conference travel.

PS What about after the PhD?

DM What then happened is that I was looking for a job. I hadn't completely settled on an academic job. I remember going to British Gas, called the Gas Board back then. They were looking for operations researchers to design the gas grid, but I didn't get that one. The University of Edinburgh Sociology Department was essentially looking for someone to teach statistics, so that's how I got my job here, not as a sociologist of science but as 
someone who could teach statistics in a way that was accessible to sociology undergraduates.

\section{Growth and Turning Points}

PS Let's move to a broader scope, STS, the history of the field in the sense of its trajectory. How do you understand the origins of STS as something unique, as something that is a field?

DM It's one of those classic questions which of course depends on how you conceptualize the object, indeed even what the letters STS are an acronym for. In other words, are they an acronym for "science and technology studies," or "science technology and society?" The second of those I would think had some sort of identity even before I started doing my $\mathrm{PhD}$, in other words by 1972. I think that term had a certain connotation of the kind of thing that David Edge was interested in, and the kind of thing that say, the British Society for Social Responsibility in Science concerned itself with, which was a little bit more public policy oriented.

PS Or interventionist in a sense?

DM Yes, to a degree at any rate. Whereas STS construed as science and technology studies I would say is a more recent phenomenon. Science studies is of course quite old, you could certainly trace it back to the creation of a Science Studies Unit and the journal Science Studies. But I'm not sure that it really became science and technology studies much before the 1980s. I think that's where say, that meeting at Twente that I mentioned was quite important, in that it brought together people within the sociology of science who had started working on science but had moved over to work on technology, like myself and Trevor Pinch. It brought people together with historians of technology, above all Tom Hughes, but also for example, Ruth Schwartz Cowan. I can't remember whether Ruth was at the meeting at Twente, but I would certainly see her as one of the historians of technology that shared similar interests. That's how I would answer the question: that science, technology and society has roots that at the very least go back into the 1960s and even earlier if you were to construe someone like J.D. Bernal as a contributor to that field. Whereas science and technology studies in the sense of the kind of thing that now gets published in the journal Social Studies of Science or in Science, Technology and Human Values, I'd see that as not really coalescing much before the 1980s.

PS What do you think are other key moments in the trajectory of STS?

DM I think one certainly was the emergence of ethnographic work on contemporary science, so the work of Bruno Latour, of Karin Knorr-Cetina, or slightly later Sharon Traweek, and the whole host of other people that obviously followed them. Because a lot of the empirical work, the earlier empirical work in sociology of scientific knowledge had been historical work like my own. Most of the PhDs in the Science Studies Unit in the early years where pieces of historical work. So I think that was very important in enriching the field. 
PS In which way? What did it bring to the field?

DM Most obviously a different methodology, and I suppose an emphasis on the laboratory, obviously developed in a different, more historical way by Shapin and Schaffer. But it would be interesting to know whether they would have the same focus on the laboratory if it hadn't been for this earlier generation, by that point it was a slightly earlier generation, of ethnographic work. So I think that's been a very important addition to the field. Then from early on, relatively early on at any rate, gender studies of science and technology became important. My own collaboration with Judy Wajcman on our reader, The Social Shaping of Technology from 1985, and the kinds of authors like Ruth Schwartz Cowan and Cynthia Cockburn that we were able to draw on, the development of feminist work on sciences as well as technology. That would be my starter list.

PS What do you see as not just key moments but say key actors or ideas that appeared or became important, key papers or publications in general?

DM I think that would be a very long list. A kind of simple, albeit tediously protracted and partial way of answering the question would be to go through the various winners of the Bernal Prize ("partial" because the prize tends not to be awarded to those outside the mainstream).

PS Perhaps which were particularly important to you over the course of your career and your various projects.

DM Inevitably, what that shows is something much more idiosyncratic. So just to give an idiosyncratic list for me, some of which people have had wider influence, some of which have not. A very important early influence on me was the historian Gary Werskey, whose name is probably not known to many people in the field nowadays. I shared a house with Gary in my final year as an undergraduate, a big communal house in Newhaven, and he had just joined the Science Studies Unit as its historian at that point. He was the predecessor of Steve Shapin in that role, and I learnt a great deal from Gary about being a historian, which of course as a maths undergraduate I knew nothing whatsoever about, so that was very valuable. And then I think that for me, and this is I think the case for a lot of people, the engagement with Actor-Network Theory became very important, both in the work I did in technology and then in the subsequent work on financial markets. I'm of a generation of people in the field who as it were, were there before Actor-Network Theory. Latour and Woolgar's Laboratory Life was relatively early. It was 1979, but even that was not really a full-fledged Actor-Network work. It was only with Science in Action in 1987 that the full contours of Actor-Network Theory started to become evident and as everybody knows, different people had very different reactions to Actor-Network Theory. I've always found it engaging and stimulating. I don't think I ever would have counted myself as a fully signed-on Actor-Network theorist but there's no doubt that the questions that it prompts you to ask are to my mind interesting and productive ones, even if you don't necessarily answer them in quite the same way. 
PS Your own research career has taken you to a lot of different places, a variety of topics from statistics to now financial markets, and many things in between. Do you see a thread that runs through all of the different projects?

DM Two tenuous connections. One is that just about everything I've looked at has got a strong mathematical element to it, which is where having done a degree in applied maths turns out to be helpful. And indeed in a rather boring cover picture of my book Statistics in Britain, there is a representation of the two-dimensional Gaussian distribution, even that distribution has kept reappearing in different forms and different pieces of work because there's an element of that in missile guidance, there's an element of that in the models that were important in the credit crisis. So there's a certain technical thread. There's also something that has taken me a while to realize. I've done two kinds of things: one is things that are I hope of considerable academic interest if not much wider public interest, and then there are things that are of wider public interest. I think I've gradually realized I get more fun studying the second of those. Examples of that would be the stuff on missile guidance and the stuff on finance, and examples of the first would be my work on statistics and my work on the mechanization of mathematical proof.

PS What is it about the second type of work that you find more fun?

DM It's just that if you're at a party and somebody asks you what you do, and what you're working on, you don't want their eyes to glaze over as soon as you start telling them.

PS Do you think that that type of work allows you to engage with a wider spectrum of groups?

DM Absolutely, yes.

PS What is that experience like?

DM It's got two main forms. The work I did on nuclear missile guidance and the like, I was a member of the Campaign for Nuclear Disarmament (CND). I still am a member of CND, so I had some direct involvement in campaigning and the like. But also I particularly enjoy writing for outlets that are read not just by my fellow sociologists and STS scholars but by wider publics, and most of that at the moment I do via the London Review of Books $(L R B)$, and that's great fun. It's partly just fun being edited by an $L R B$ editor because to write for the $L R B$ you've to write in a very different way from academic publications. Just a couple of weeks ago, I was moderating first-year essays and telling people what they should have done in terms of good academic essay writing, and then correcting the proofs of a little $L R B$ piece, where all the remaining traces of the kind of thing that our students were being told to do, all the remaining traces of that in my manuscript had been expunged by the $L R B$ editors.

\section{"Tacit Moral Obligations" and the Politics of Research}

PS You've mentioned political commitments in a number of different ways. You referred to yourself as a radical. Do you think any political commitments have characterized STS since the earliest years when you became involved with the field? 
DM I think there is no doubt that the vast majority of people in the field are on the left of the political spectrum. But that's of course not unique because one of the things that's happened is that academia, at least in the two countries I know best, Britain and the United States, has moved to the left as a whole over the past 50 years. I seem to remember statistically in the middle of the 1950s the majority of British academics voted Conservative, which is unthinkable nowadays. So there's a certain generic left-wing position. There's a strong feminist position. I guess a strong commitment to anti-racism but that doesn't actually reflect itself perhaps in the overall academic work in quite as evident a way as the feminist commitment does. The one thing I would say, just in relation to my own work, is that being an STS researcher of an empirical, almost ethnographic kind, and being a political activist are not things that sit very easily together. To do what we do you have to learn how to see the world as the people who you're studying see the world. You've got to get into their heads in a certain way, and that actually changes you as well as changing what you write. So that I now see virtues in markets that 30, 40 years ago I simply didn't see. A way of putting it is: I was once temporarily supervising a feminist scholar who was working on artificial reproductionlet's say for the sake of simplicity test-tube babies-and I just thought the most natural thing for her to do would be to go interview the medical figures in Britain who pioneered that practice. But she came from a feminist viewpoint that was deeply suspicious of medically-assisted reproduction, and she didn't want to interview them. At the time I thought that was just wrong-headed, but now I realize that she was actually right. The process of doing interviews, or ethnographic fieldwork more generally, first of all has that kind of effect on your thinking, but secondly it involves you in tacit moral obligations. Interviewing in the nuclear weapons complex or the financial sector is different from fieldwork with academic scientists or researchers in many other contexts. Those in the nuclear weapons complex are bound by security classification rules backed by harsh criminal penalties. Of course, those I spoke to were well aware of those rules and careful not to transgress them. Nevertheless, my interviews were trying to "open the black box" as far as possible, and it was always conceivable that an interviewee might inadvertently breach security rules in seeking to answer my questions. So in speaking to me they were taking a certain risk. The same is true for interviewees in finance (certainly, in the years since the crisis; things were more relaxed before it). The risk there is of course not imprisonment, but dismissal. Many organizations in finance prohibit their employees from speaking to the press without the presence of a member of the corporate public relations staff, and in some organizations an academic who does the kind of work I do could be classed as equivalent to a journalist. Even organizations without this formal policy might very well discipline or dismiss an employee who said too much about trading strategies, for example. If I had say, interviewed my nuclear weapons designers and then written a book that condemned them as warmongers and so on, I think I would just have been acting unethically because I was as it were accepting their hospitality, so you can't accept someone's hospitality and then denounce them. When my book 
Inventing Accuracy came out, Langdon Winner criticized its tone very sharply. For example, at an author-meets-critic session at the Society for Social Studies of Science meeting in Gothenburg, basically saying that I should have condemned the enterprise, and I just found it morally impossible to do so. So I think that's an aspect that anyone in STS who's working on politically controversial topics needs to bear in mind.

PS What is the relationship between say that commitment, that obligation, and this aspect of STS that has seen it as being interventionist and advancing particular political commitments?

DM I think that it's perfectly compatible with interventionist policy. For example, in the current work I'm doing in high-frequency trading, there's a book by Michael Lewis- the author of Liar's Poker - on high-frequency trading called Flash Boys. "They're villains," is the story that he tells, and I couldn't possibly write my own equivalent of Flash Boys for the reasons I've just outlined. But that doesn't mean that it's not possible to think about interventions in market structure and to be very confident about it. It's reasonable to think that there is an arms race element in high-frequency trading, a race for speed and I think even high-frequency traders themselves would say to you that in some respects that race for speed benefits no-one in the sense that it's a zero-sum game kind of thing. For example, there's a guy named Manoj Narang who headed the high-frequency trading firm Tradeworx, talking about a potential new fast transatlantic cable and saying exactly that: it wouldn't benefit anybody. It would be a tax on the industry, everybody would have to pay the very high fees for using it and nobody would be making any greater profits because of it. So there's an arms race element to it, and it's difficult at least at this stage in my research to know how important that arms race element is compared to other aspects of it. But I've got interested in the work of a man called Eric Budish, an economist at the University of Chicago, who argues that there's a flaw in the basic design of the majority of Western financial markets, which is basically to do with the fact that buys and sells, bids and offers, are matched continuously in those markets, which is what creates the incentive for speed and Budish argues that a relatively simple reform changing to not matching continuously but matching every second or even every tenth of a second would remove the race for speed and the costs associated with that while keeping the benefits, and there are real benefits that automation brings. So I can quite see that kind of argument is compatible with the moral obligations of the fieldworker, but doing the Michael Lewis—"they're all scary villains"—isn't.

PS So you're talking about our relationship as researchers to groups, in your case economists, but also scientists and technologists in other fields. How do you see our relationship to other groups, say other fields in the social sciences?

DM I suppose that question is very varied, according to what field one's talking about. I think the kind of area that I'm working in, sometimes called the social studies of finance, which involves not just this but includes people bringing STS perspectives to bear on financial markets, can have and has had a productive dialogue with economic sociologists. There's a bit of guerrilla warfare occasionally but I think basically I've found the dialogue 
productive. I think one's got to be careful as an STS person not to go in and do a simple, "oh you people are all so old-fashioned because you think social relations are just amongst human beings but listen to me telling you about the role of non-humans and social relations and that'll change everything." You can do it in an aggressive way that is never going to convert anyone, but you can also do it by saying, "well, attention to technical systems, to the role of non-humans, etc., etc., etc., usefully develops and complements existing perspectives." I suppose what I'm saying is: with a modicum of modesty and good manners, generally make friends and influence people.

PS What about groups and policymakers, government officials?

DM The issue there of course is that one has got to have a realistic view of what policymaking involves, and that's to say policymaking is a very constrained activity and if you really want to influence policy then you've got to be in the right place at the right time and to be saying things that can articulate with the particular issues and concerns and constraints on policymakers. I've never very specifically tried to do that; if that were ever to happen I think it would be good luck rather than good judgment. So I suppose in terms of my own work all I would hope to achieve is just maybe enriching the debate somewhat. I gave a talk at the Bank for International Settlements in Basel earlier this year, that's the body that hosts the Basel Committee on Banking Supervision that sets the capital adequacy standards for world banking. My talk wasn't about capital adequacy standards, and they know more about capital adequacy standards than I do, but I talked about the use of mathematical models, particularly in investment banking. Afterwards somebody said something I was very pleased to hear. He said, "You made explicit things that we know go on but don't talk about." So I think there's some use to doing that, but it would be silly of someone in my situation to think that they're at all likely to have much of an influence on the setting of financial policy, because the forces that are at work in forging that are very big and very problematic, so it would just be naïve to think that a nice little bit of research is going to have much direct impact.

PS You mentioned writing for the London Review of Books. How do you see the field's engagement with a variety of publics? What has your experience been engaging with different publics?

DM I think it is something that intrinsically varies according to what particular type of research that you're doing, so that my colleagues who've worked on genetics and biotechnology have absolutely had much more direct engagement than I've ever had, because those are things that obviously bear in a very direct sense on questions of personal identity and also on political divides that are already there. Whereas there are other areas where what one's simply doing is to try to make things that are otherwise opaque and mysterious, a little more open to public view. In the Edinburgh Book Festival this year I went to a talk by John Lanchester, who is a novelist but who's also started to write about finance in the London Review of Books, and that's very much what I think he sees as his mission: opening up this complexity. He said in the middle of his talk, which is also in a piece by him in The New Yorker, which if I remember the wording exactly, that 
"incomprehension is a form of consent." So I think there is a certain virtue in providing materials that will help someone that wants to understand to understand a little bit better.

PS So opening up the black box as a kind of public service?

DM Yes, absolutely.

PS Do you find that your work on financial markets has become more relevant since the 2008-2009 crisis and the focus on these social dynamics?

DM Yes, absolutely. There was plenty of stuff before that, crises that seemed big crises at the time but don't seem big crises after we've had the really big crisis. But yes, absolutely. What we've learned is I think that financial capitalism is inherently unstable and that wasn't something that was clear in advance.

\section{Successes and Unfinished Work}

PS Let's talk about STS now and STS in the future. How do you view the field right now? How would you describe it?

DM I think the first thing I should say is I'm not actually necessarily very well placed to answer that question, because I tend not to go to very many STS meetings for the simple reason really that I'm working in a rather specialized area and also the kind of work I do involves a lot of overseas travel. And of course also I don't teach in an STS department, I teach in a sociology department. So I'd have to qualify anything I was to say with pretty big provisos that I'm not necessarily that in touch with how the field currently is developing. I think what I probably want to say would be two things. First of all, unquestionably it's been very successful over the last decade, decade and a half, perhaps even two decades, in spreading its influence into the humanities and social sciences more widely. My daughter, for example, is working on a PhD in English literature and she told me that Bruno Latour was now amongst the 20 most cited figures in the humanities. In terms of things I'm more directly closely connected to, if you think about a discipline like human geography, it has very strongly been influenced by science and technology studies. So the field is unquestionably a success story if you measure success in influence on surrounding social sciences and even in some respects the humanities.

PS Do you think that there are particular lessons or concepts or perspectives that have allowed for this success, that have been the ones that have been picked up and driven our influence?

DM Yes, I think so. I think the Strong Program and the idea of social construction certainly did have a big influence. But of course, unfortunately, it was largely an influence based on a misconception of what the Strong Program was about and what the idea of social construction of knowledge actually meant in the minds of those who were putting it forward. So that was an unquestionably successful influence but of a rather bizarre, almost negative kind. Then the other thing that clearly has attracted a lot of attention is Actor-Network Theory, and I suppose very specifically Bruno Latour. All sorts of people 
in all sorts of disciplines get some kind of inspiration from Bruno's work. So I think other areas of work have been influential in very specific ways but I think those have probably been the two biggest forms of influence.

PS What do you think STS hasn't done yet? Where hasn't it gone that maybe it should go?

DM I think that was the second thing I was going to say. We shouldn't think that the sociology of scientific knowledge or the social construction of scientific knowledge, we shouldn't think that that's a solved problem. And I think there has been a certain danger that people entering the field have thought of that as something that's been solved, and of course it isn't. We've little snippets of insight into how scientific knowledge is socially formed but there are vast spheres where we know next to nothing, and the most obvious one is mathematics. Think how little work of a sociology of knowledge kind, whether historical or ethnographic, has actually been done on mathematics, and the best stuff is actually by historians of mathematics themselves who've turned their work in directions consistent with the sociology of scientific knowledge. But there's huge areas where we know next to nothing, so that it's a mistake for people if they think that those sort of things, we know the answers for that because actually we don't, or at least we don't in anything other than the most abstract formulaic kind of way. I'm sure much the same could be said of much of physics and chemistry, for example. Biology I think has received much more attention, partly for funding reasons in the last few decades. And then of course what there also is, is vast areas of modern life which aren't sciences in the classic fashion, but are in some sense techno-scientific. Finance is one but there are hosts of others, where again we've really only scraped the surface. If you think about, for example the role of algorithms in modern economic life, which is something people in the social studies of finance, including myself, have started to look at, you get what I'm afraid I sometimes think of as just philosophical commentary on algorithms in economic life, but a whole host of things that we don't really know or never have been properly studied in any kind of ethnographic way. So, those two things: there's a lot still to be done in the sociology of the classic sciences, including mathematics; and secondly, that modernity after all is a techno-scientific project and there are vast areas of that project that we also don't understand.

PS If you were to give say directives to the next generation of researchers...

DM If I started doing that I think I would say, "that's time to retire, Donald."

PS Maybe inspirations or suggestions?

DM I think one suggestion is, I'm afraid, learn some science when you're young. Because I do think that there's just something about the human brain that makes it easier to learn technical subjects and also difficult languages when you're young than when you're older. Whereas social science conceptualizations and so on are, this is my personal experience, are rather different from that. So I think that is something that's just practical stuff that I've learned that's been hell of a useful for me, as I've said a couple of times in this discussion. It's been a hell of a useful to me that my first degree was applied mathematics. I've forgotten nearly all of it but there's just something about having done 
it that gives you a certain confidence that if you really need to understand something, when you put the work in you will be able to understand it.

\title{
The Place and Power of Discomfort in STS
}

\author{
By PABLO SCHYFTER
}

\begin{abstract}
"I was a radical," Donald MacKenzie recalls. The comment, early in the interview and delivered in a somewhat offhand fashion, brought both a smile to my face and a great many notes to my pad because it seemed so incongruous with the person sitting in front of me. But as he recounted his entry into STS, MacKenzie told me the story of an undergraduate science student in Edinburgh drawn to radical meetings on, and intriguing new ideas about, science. His first encounter with the Science Studies Unit (SSU) occurred at the Edinburgh branch of the British Society for Social Responsibility in Science (BSSRS). There, he met David Edge, a prominent figure in the Society and founder of the SSU. In a sense, Donald MacKenzie entered STS by way of political activism.

And yet, in reviewing and reflecting on the field MacKenzie stressed that investigating science and technology, and participating in political activism concerning science and technology, do not sit together unproblematically. The STS researcher and the STS activist, of course, are not irreconcilable identities, but neither are they identities in effortless harmony. Thus, who the STS researcher is, and what she does, evince tensions and challenges frequently encountered and worthy of study.

MacKenzie reflected on these issues by considering "tacit moral obligations" of the researcher. I believe that these reflect and speak to other, kindred obligations of the field and its work. All suggest the importance and various roles of discomfort in STS.
\end{abstract}

\section{Moral Obligations}

MacKenzie's thoughts about STS during the interview rarely took the form of a general overview. Instead, he presented a personal narrative, from which he drew observations and lessons. Among these are thoughts on the "tacit moral obligations" that follow from our entry into research spaces and from the participation of those we study. He does so by pointing out a simple, but consequential reality of social scientific research. Scientists and technologists' "hospitality," as he terms it, binds us to important ethical commitments, and ought to condition our interventions and our activism. 
At first, "hospitality" seems a trite concept, or an over-generous term for what scientists and technologists give the STS researcher. Words like "entry" or "access" might capture the reality of empirical work more effectively, and avoid portraying scientists and technologists as benevolent hosts. And yet, terms like those carry connotations of disinterested, uncomplicated transaction. They do not suggest the moral obligations, tacit and otherwise, that MacKenzie argued exist and matter.

To make this point, he reflects on his own experiences in studying experts in politicallycontentious fields of public interest. Namely, he discusses his work on nuclear missile guidance (1990) and his studies of practitioners in high-frequency trading (2006). Obviously, his work required the cooperation of research subjects; this dependency is one common to all social science projects of the kind. As such, while his experiences are particular, they are neither unique nor unfamiliar. All social scientists intending to interview and aiming to observe rely on some form of reception and some degree of openness from those interviewed and observed. As did the term "hospitality," this fact seems fairly banal. And yet, it offers a useful way to think about what we as STS researchers do, our commitments and responsibilities, and how the field is, and may be, politically active.

MacKenzie's two examples, nuclear weaponry and contentious financial practices, are unquestionably and intractably characterized by debate and disaccord. Ignoring such politics makes no sense for a field in many ways defined by a search for and study of those politics. And yet, MacKenzie's projects both required the openness of practitioners; in both cases he benefited from their cooperation. His acceptance of their "hospitality" is a political act, with political ramifications. Both times, he felt that any attempt to "denounce" them-to censure them as unqualified wrongdoers-would neglect and debase the help those practitioners provided. His book on missile guidance, Inventing Accuracy, was criticized by some for not "condemning" work to develop sophisticated guidance mechanisms. Nonetheless, he felt it "morally impossible" to do so, just as he felt it improper to portray high-frequency traders as villains of the Great Recession.

MacKenzie emphasizes the "tacit moral obligations" of "hospitality," but he does not call for political agnosticism or equivocation. He neither celebrates the participants, nor suggests a need for deference. As such, the issue is not the researcher "playing nice," "being polite," or "knowing her place," but rather being aware of implicit commitments and normative responsibilities, and operating with a critical lens on her own practice. For instance, activism aimed at high-frequency trading can be served by lucid, sophisticated analyses of innate flaws and dangers in market structures. Though MacKenzie presents the ideas using examples from his personal experiences and in terms of the single researcher, issues of "tacit moral obligations" concern the field, its knowledge, and what that knowledge can be used to accomplish.

\section{Epistemic Obligations}

MacKenzie's observations and arguments about "tacit moral obligations" focus on methodological and rhetorical issues and researchers' responsibilities to those they study. 
However, his claims mirror other kinds of commitments and obligations. The first of these concerns the epistemic character of STS.

The earliest work in STS followed from an epistemic impulse to complicate our understanding of science and technology. Efforts like the sociology of scientific knowledge and laboratory studies responded to what some saw as generalized, abstract philosophies of science. Key arguments sought to dismantle the epistemic privileges enjoyed by scientific knowledge,, and key empirical work set out to document and analyze the lived, messy realities of scientific practice. Sociological research and relativist theories together served to find the particularities, nuances, and contingencies that characterize science and technology. Shared tenets, concepts, methods, and ambitions made possible a plethora of diverse investigations. These, while distinct in their accomplishments, nonetheless share basic epistemic commitments. I contend that this includes an interest in delivering critically-sophisticated analyses and in veering away from earlier, simpler perspectives. MacKenzie's study of nuclear missile guidance (1990) and Pickering's study of particle physics (1986) differ in many important ways. However, they share a desire to bar critical simplicity and reveal unacknowledged complexities. In this sense, one important aspect of STS is that it has established an epistemic obligation to forego the serenity of abstractions and generalizations and has embraced a very useful form of discomfort. Namely, the discomfort of no absolutes and of persistent potential for revelations that challenge what we hold to be true.

Work in technology studies similarly championed a form of epistemic discomfort. Constructivist research set down to overturn portraits of technology based on simple determinism or technological neutrality, and to offer instead sophisticated accounts of technology as a social institution. Langdon Winner's bridges (1971), Cynthia Cockburn's printing presses (1981), and Bruno Latour's door-closers are not indifferent material, but rather artifacts molded by and actively engaged in a constellation of social dynamics. Winner's iconic claim that "artifacts have politics" encapsulates the field's impatience with the notion that technology is just stuff. Again, STS demanded a renouncing of comfort; in this case, the comfort of technological neutrality and passivity.

Such commitments and obligations unquestionably remain central to STS work, serving in many ways as guiding principles and ends to accomplish. In this sense, STS is a project in compounding complexities. I view MacKenzie's thoughts on research relationships as ones that fit this enterprise well. Work that aims to make contingencies and complexities clear should acknowledge the contingencies and complexities that characterize research relationships. Research that rejects simple and comfortable stories about science and technology ought to challenge simple and comfortable views on its own work. It should not sit cozily with clear-cut politics and simple critique. Its self-reflection ought to be uneasy.

And yet, since its earliest days STS has examined and committed itself to a variety of critical missions outside of the academic project. Breaking open the many black boxes of science

${ }^{3}$ For example, Bloor (1976) and Latour (1987).

‘ For example, Latour and Woolgar (1979), Knorr-Cetina (1999), and Pickering (1986).

${ }_{5}$ This article was published under a pseudonym: Johnson (1988). 
and technology has followed from critical aims, some explicitly concerned with political intervention. MacKenzie's encounter with David Edge at the BSSRS is an interesting example of political commitment, but hardly the only one. Some types of STS by definition form part of political activism. For example, feminist STS-a type of work MacKenzie discusses and praises, and one in which I have worked-is characterized fundamentally by critical and political commitments." Other types of work, such as some of those involving policy issues, seek to intervene politically. And of course, work that forms part of expansive science and technology research projects is entangled in all manner of responsibilities and commitments. Crucially, much of this STS research reflects a not uncommon sense of critical obligation: STS ought to employ its understanding to intervene and influence.

\section{Critical Obligations}

Many of those interviewed for this project, including MacKenzie, draw attention to important distinctions between STS construed as "science and technology studies," and "science, technology, and society." For MacKenzie, the latter is more directed at intervention, and came together earlier than did the former. Work like that of David Edge and the BSSRS involved academic study aiming at impact broader than academia. Contemporary work that involves direct engagement with policy and participation in techno-scientific research enterprises also sets out to intervene and influence in many different ways.

MacKenzie acknowledges the importance of such ambitions, but again notes the moral obligations and political restraints that accompany "hospitality." We are bound by responsibilities to those we criticize, and a choice to dismiss those responsibilities is a political choice with political implications. It's also a choice for comfort. Acknowledging a form of implicit liability and accepting its boundaries is more challenging than unqualified criticism. And yet, it is a choice more harmonious with a fundamental ambition of STS: to undermine the comfort of simplicity.

It appears to me that MacKenzie's thoughts on STS and its work involve three types of obligations: "tacit moral obligations" to those practitioners whom we study; epistemic obligations to our research undertakings; and critical obligations as agents involved in expansive and significant social debates. All three are bound by a commitment to complexity. MacKenzie argues that unpacking the social and technical intricacies of markets-an epistemic aim-can serve to challenge unsafe practices-a critical aim. Importantly, intervention of this kind avoids the type of condemning that overlooks our obligations to those we study.

Perhaps a fruitful construction of "critical obligations" partners two calls: first, a demand for STS to get out there and "do something"; second, an expectation that in doing so, we will embrace reflexive discomfort.

- The feminist STS literature is expansive. Some useful examples include: Keller (1995), Haraway (1988), Tonso (1999). 


\begin{abstract}
Author Biography
Donald MacKenzie is Professor of Sociology at the University of Edinburgh. His work has examined the place of mathematics in a range of fields, including statistics, nuclear missile guidance, computerized proof, and financial markets. Currently, he studies automated highfrequency trading and the use of financial models. As an undergraduate student of mathematics in Edinburgh, MacKenzie was drawn to the sociology of knowledge by the founders of the Science Studies Unit (SSU) and their participation in political activism. Throughout his doctoral studies at the SSU, MazKenzie formed part of a group whose ideas served the making of science and technology studies (STS). Since, then, his research has contributed exceedingly to the growth of STS. Although he now casts himself as somewhat of an outsider, MacKenzie's texts and arguments continue to be relevant and important parts of the field. Moreover, his more recent writings in outlets like the London Review of Books have served to convey important STS ideas to broader audiences, and to foster debates about the role and shape of modern financial markets.
\end{abstract}

\title{
Author Biography
}

Pablo Schyfter is a Lecturer in Science, Technology and Innovation Studies at the University of Edinburgh. His research has focused on the gendering of technological artefacts and professions, and on various facets of synthetic biology, a nascent biotechnology field. Much of this work has aimed to develop conceptual and theoretical partnerships between different social scientific and philosophical schools. These include post-structuralist theories of subjectivity, phenomenological writing on technology, and pragmatist conceptualizations of knowledge. Currently, he is studying the building of masculinities in synthetic biology.

\section{References}

Bloor, D. 1976. Knowledge and Social Imagery. Chicago: University of Chicago Press.

Cockburn, C. 1981. "The material of male power." Feminist Review, 9:41-58.

Haraway, D. 1988. "Situated knowledges: The science question in feminism and the privilege of partial perspective." Feminist Studies, 14(3):575-599.

Johnson, J. 1988. "Mixing humans and nonhumans together: The sociology of a door-closer." Social Problems, 35(3):298-310.

Keller, E.F. 1995. "Gender and science: Origin, history, and politics." Osiris, 10:27-38.

Knorr-Cetina, K. 1999. Epistemic Cultures: How the Science Make Knowledge. Cambridge, MA: Harvard University Press.

Latour, B. 1987. Science in Action. Cambridge, MA: Harvard University Press.

Latour, B. and Woolgar, S. 1979. Laboratory Life: The Construction of Scientific Facts. Princeton, NJ: Princeton University Press.

MacKenzie, D. 1990. Inventing Accuracy: A Historical Sociology of Nuclear Missile Guidance. Cambridge, MA: The MIT Press. 
MacKenzie, D. 2006. An Engine, Not a Camera: How Financial Models Shape Markets. Cambridge, MA: The MIT Press.

Pickering, A. 1986. Constructing Quarks: A Sociological History of Particle Physics. Chicago: University of Chicago Press.

Tonso, K.L. 1999. "Engineering gender - gendering engineering: A cultural model for belonging." Journal of Women and Minorities in Science and Engineering, 5(4):365-404.

Winner, L. 1980. “Do artifacts have politics?" Daedalus, 109(1):121-136. 